\title{
A STUDY OF COLOUR VISION IN NON-INSULIN-DEPENDANT DIABETES MELLITUS (NIDDM) SUBJECTS
}

\author{
S. Vadivel ${ }^{1}$, M. Vijayamalathi ${ }^{2}$
}

${ }^{1}$ Professor, Department of Physiology, Karpaga Vinayaga Institute of Medical Sciences and Research Institute, Madurantagam, Kanchipuram, Tamilnadu.

${ }^{2}$ Assistant Professor, Department of Physiology, Karpaga Vinayaga Institute of Medical Sciences and Research Institute, Madurantagam, Kanchipuram, Tamilnadu.

\section{ABSTRACT}

This study was designed to evaluate the colour discrimination defect as an early indicator of diabetic retinopathy. The subjects were of two groups. Group-I consisted of individuals with diabetes mellitus type-II and group-II consisted of non-diabetic individuals. Both the groups were between 30-70 years of age with corrected acuity of vision and without diabetic retinopathy. They were subjected to colour discrimination test using Farnsworth-Munsell 100 Hue test. The results revealed that more number of subjects were affected with blue-yellow axis and lesser number were affected with red-green axis in group-I compared to group-II. This study confirms that colour discrimination defect is one of the early changes of diabetic retinopathy.

\section{KEYWORDS}

Diabetes, Colour Vision, Diabetic Retinopathy.

HOW TO CITE THIS ARTICLE: Vadivel S, Vijayamalathi M. A study of colour vision in non-insulin-dependent diabetes mellitus (NIDDM) subjects. J. Evolution Med. Dent. Sci. 2016;5(65):4647-4649, DOI: 10.14260/jemds/2016/1059

\section{INTRODUCTION}

Diabetes mellitus is a metabolic disorder due to defects in insulin secretion, insulin action, or both characterised by hyperglycaemia, altered metabolism of lipids, carbohydrates, and proteins with increased risk of complications from vascular diseases. The first systemic description of diabetes mellitus was written by Aretaeus of Cappadocia in first century A.D. ${ }^{1}$ He described the disease as "melting down of flesh into urine".

Diabetes is one of the leading causes of blindness in India. ${ }^{2,3}$ This fact has driven us into this expedition of evaluating non-retinopathic diabetic individuals. Diabetes as such is one of the leading ailments for the disabling morbidities as per the world epidemiological studies. Based on the current trends, the International Diabetes Federation projects that 592 million individuals will have diabetes by the year 2035.

Diabetic complications can be divided into vascular and nonvascular. Retinopathy, neuropathy, nephropathy are the vascular complications and coronary heart disease, peripheral heart disease, and cerebrovascular disease being nonvascular.

Screening of the population for this dreaded disorder is very important as many studies show that the present scenario manifests itself even after a decade of dormant presence. Many studies stress the importance of evaluation of prediabetic stage as it develops complications before manifesting clinically.

Hyperglycaemia results in glycosylation of various tissues resulting in dreadful complications, one of it is diabetic retinopathy.

Financial or Other, Competing Interest: None.

Submission 07-03-2016, Peer Review 30-05-2016,

Acceptance 06-06-2016, Published 13-08-2016.

Corresponding Author:

Dr. M. Vijayamalathi,

Assistant Professor,

Department of Physiology,

Karpaga Vinayaga Institute of Medical Sciences and

Research Institute, Madurantagam, Kanchipuram,

Tamilnadu.

E-mail:dr.vijayaamar@yahoo.com

DOI: $10.14260 /$ jemds/2016/1059
Recent studies suggest that good glycaemic control ${ }^{4}$ will defer or prevent the chronic complications of diabetes mellitus.

One of the manifestations of diabetic retinopathy is impairment of colour vision. Colour sense is the ability of the eye to discriminate between colours excited by light of different wavelengths. Colour vision impairment is substantiated by spectral sensitivity measures, which is assessed and evaluated against the control group.

Recently, it has been documented that there is a decreased sensitivity in cone pathways in patients with early diabetic retinopathy. Despite these findings, there is disagreement in the literature to various tests of colour vision, its interpretation, and its association with diabetic retinopathy. ${ }^{5}$

In view of these conflicting reports, we have taken one of the five special senses for our study. Our study dwells deeply into assessing the aberrations of light perception namely colour vision in a select group of diabetes mellitus type II (NIDDM) who showed no evidence of early background retinopathy.

\section{AIM}

To create awareness among NIDDM individuals, the role of colour vision in containing the glycaemic status.

\section{OBJECTIVES}

- To measure short wavelength sensitivity of NIDDM subjects and controls.

- To evaluate the results of both the groups.

\section{MATERIALS AND METHODS}

This study was conducted in the Outpatient Clinics of Diabetology Department, Government General Hospital and in refraction room of Sankara Nethralaya Eye Institute, College Road, Chennai, after getting the approval of institutional ethical committee and the written informed consent of the volunteers. Test group consists of Group I: 85 patients of noninsulin-dependent diabetes mellitus without diabetic retinopathy, on oral hypoglycaemic agents between the age group of 30-70 years were recruited. 
All the subjects in this group had antidiabetic treatment ranging from 3-20 years.

Group II: 85 non-diabetic subjects of age group between 30-70 years with no known abnormality of visual system comprised the control group.

\section{Exclusion Criteria}

Care was taken to eliminate patients with history of familial colour vision deficits or congenital colour blindness, chronic diseases not associated with diabetes, history of any ophthalmological disease, gross visual impairment, and advanced cataract.

\section{METHODS}

- Blood glucose both fasting and postprandial was estimated by orthotolidine method.

- Visual acuity was assessed by using Snellen's chart. The subjects who had corrected visual acuity of about $6 / 9$ or $6 / 6$ of both eyes were included in this study.

- Colour discrimination was assessed monocularly by Holmgren wool test, Ishihara plate test, and the Farnsworth-Munsell 100 (FM 100) Hue test under appropriate lighting condition.

All the subjects underwent comprehensive eye examination including fundus evaluation.

\section{RESULTS}

The diabetes mellitus (NIDDM) subjects formed group I and non-diabetic control subjects formed group II. The analysis of fasting and postprandial blood sugar values, visual acuity, Holmgren wool test, Ishihara test, Farnsworth-Munsell 100 (FM 100) Hue test, and fundal examination are as follows:

\begin{tabular}{|c|c|c|}
\hline Parameters & Group & Mean Value \\
\hline \multirow{2}{*}{ Fasting blood sugar } & I & 9.9647 \\
& II & 5.4588 \\
\hline \multirow{2}{*}{ Postprandial blood sugar } & I & 15.8353 \\
& II & 7.2471 \\
\hline
\end{tabular}

Visual Acuity: (In both eyes).

Group I: 6/9 in 78 subjects, $6 / 8$ in 7 subjects.

Group II: $6 / 9$ in 47 subjects, $6 / 6$ in 38 subjects.

Holmgren Wool Test: (In both eyes)

Group I: (Out of 85 subjects).

Normal vision: 55 .

Colour mismatch: 30 ( 22 had blue-yellow deficiency, 8 subjects had red-green deficiency. Out of these 8 subjects, 5 subjects were deuteranope and 3 subjects were protanope.

Group II: Out of 85 subjects, only two had impairment of colour vision.

\section{Ishihara Plate Test}

Group I: (Out of 85 subjects) Red-green deficiency: 16 (8 protanopes, 8 deuteranopes).

Group II: Out of 85 subjects, one had red deficiency and one had green deficiency.

\section{FM 100 HUE TEST}

Group I: Average colour vision: 55, an error score between 20100.

\section{Low Colour Vision}

30 (22 had low colour discrimination towards blue yellow axis with error score above 100, 8 subjects towards red green axis and error score above 100).

Group II: Out of 85 subjects, only two had low colour discrimination towards red green axis with error score more than 100 .

\section{Group I}

\begin{tabular}{|c|c|c|c|}
\hline $\begin{array}{c}\text { Age in } \\
\text { Years }\end{array}$ & Protanope & Deuteranope & Tritonope \\
\hline $30-40$ & - & - & 3 \\
\hline $41-50$ & 2 & 1 & 6 \\
\hline $51-60$ & - & 1 & 5 \\
\hline $61-70$ & 2 & 2 & 8 \\
\hline
\end{tabular}

\section{Group II}

\begin{tabular}{|c|c|c|c|}
\hline $\begin{array}{c}\text { Age in } \\
\text { Years }\end{array}$ & Protanope & Deuteranope & Tritonope \\
\hline $30-40$ & - & - & - \\
\hline $41-50$ & - & - & - \\
\hline $51-60$ & 1 & 1 & - \\
\hline $61-70$ & - & - & - \\
\hline
\end{tabular}

Sample size calculations were done by using previous prevalence of $39.5 \%{ }^{6}$. Based on this, we consider the clinical difference would be $15-20 \%$ for approximately 85 subjects per arm.

\section{DISCUSSION}

Colour sense is the ability of the eye to discriminate between colours excited by light of different wavelengths. Characteristics of colour are hue, saturation, and brightness. Perception of colour begins with specialised retinal cells containing pigments with different spectral sensitivities known as cone cells. In humans, there are three types of cones sensitive to three different spectra resulting in trichromatic colour vision. A normal person can see all wavelengths between violet and red. If the wavelength is shorter than that of violet, the light becomes ultraviolet and is beyond visibility. If the wavelength is greater than $750 \mathrm{~nm}$, the light is infrared and it is also beyond visibility.

\begin{tabular}{|l|l|l|l|l|l|l|l|l|}
\hline Infrared & $\mathbf{R}$ & $\mathrm{O}$ & $\mathrm{Y}$ & $\mathbf{G}$ & $\mathbf{B}$ & $\mathbf{I}$ & $\mathbf{V}$ & Ultraviolet \\
\hline
\end{tabular}

The cones are conventionally labelled according to the ordering of the wavelengths of the peaks of their spectral sensitivities: short (S), medium (M), and long (L) cone types. The perception of colour is achieved by a complex process that starts with the differential output of these cells in the retina and it will be finalised in the visual cortex and associative areas of the brain. People who are totally colour blind, a condition called achromatopsia, can only see things as black and white or in shades of gray. Colour deficiency is usually an inherited condition, but disease and injury can also result in colour recognition loss.

It has been well established that colour vision is affected by diabetic retinopathy. ${ }^{7}$ It is interesting to note that diabetic 
retinopathy prevalence was least among Indians (5.3\%) as compared to other ethnic groups like Malays (10\%) and Chinese $(15.1 \%){ }^{8}$

Our results showed that diabetic patients without demonstrable retinopathy have an increased incidence of acquired dyschromatopsia. In this study, impaired colour vision in group I NIDDM subjects were 30 out of 85 . Out of these 30 subjects, 22 subjects were tritonope, 4 protanope, and 4 deuteranope, which is in agreement with the study published by Sinha A K, Bhatia R et al. ${ }^{9}$ In group II, non-diabetic subjects out of 85,83 had normal colour vision, only 2 subjects had colour vision deficiency (One protanope and one deuteranope).

Colour vision defects in diabetes have been documented by Kinear et al who reported a high incidence of yellow blue losses among diabetics even without retinopathy.

We can create awareness among diabetic people to give priority to have absolute glycaemic control as longer duration of the disease causes greater colour vision defect secondary to chronic hyperglycaemia.

Our study finding reveals the importance of assessing the impairment of colour vision in diabetic non-retinopathic individuals, which can be used as a screening method to detect potential diabetic retinopathy before it manifests clinically.

Prevalence of ICV as reported by Shoji et al is 3.5\% ${ }^{10}$ and in another study by Gella L et al 7 is $39.5 \%$ and our study result is $32.5 \%$, which is well in accordance with the published literatures. Again, all these results reemphasises the importance of assessing ICV in diabetes without retinopathy in maintaining glycaemic control so as to prevent impending retinopathy.

In our study, we have applied three tests for detecting impaired colour vision and FM 100 Hue test is most sensitive of the three. But, more accurate result can be obtained by using Cambridge Colour Test (CCT), which detects threshold level of the cones.

\section{CONCLUSION}

Our study shows individuals in group. I had more of Tritan type, which is $25.8 \%$, Deuteranope $4.7 \%$, and Protanopes $4.7 \% .7,9$ The results arrived in this study on diabetic individuals without retinopathy reiterates the importance of maintaining glycaemic control to prevent visual complications.

\section{STATISTICS}

Blindness due to DR accounts for 3\% of blindness in India. There is no National Screening Program in India for DR. Vision 2020 e-resource.
The studies in West have given Prevalence of 3.3\%, less than 5. Considering all these on screening, 300 diabetic patients we have selected 170 eligible patients and divided them into 2 groups of 85 in each arm (a-subjects, b-control).

The sample size in this study was 85 per arm (85 in case group and 85 in control group). Sample size calculations were done by using previous prevalence of 39.5\% (Sankara Nethralaya). Based on this, we consider the clinical difference would be $15-20 \%$ for approximately 85 subjects per arm.

\section{REFERENCES}

1. Lakhtakia R. The history of diabetes mellitus. Sultan Qaboos Univ Med J 2013;13(3):368-70.

2. Barber AJ. A new view of diabetic retinopathy: a neurodegenerative disease of the eye. Prog europsychopharmacol Biol Psychiatry 2003;27(2):28390.

3. Patil S, Gogate P, Vora S. Prevalence, causes of blindness, visual impairment, and cataract surgical services in Sindhudurg district on the western coastal strip of India. Indian J Ophthalmol 2014;62(2):240-5.

4. Rockett M, Anderle D, Bessman AN. Blue-yellow vision deficits in patients with diabetes. West J Med 1987;146(4):431-3.

5. Greenstein V, Sarter B, Hood D, et al. Hue discrimination and $\mathrm{S}$ cone pathway sensitivity in early diabetic retinopathy. Invest Ophthalmol Vis Sci 1990;31(6): 1008-14.

6. Gella L, Raman R, Kulothungan V, et al. Impairment of colour vision in diabetes with no retinopathy: Sankara Nethralaya diabetic retinopathy epidemiology and molecular genetics study. PLoS One 2015;10(6):e0129391.

7. Ong GL, Ripley LG, Newsom RS, et al. Assessment of colour vision as a screening test for sight threatening diabetic retinopathy before loss of vision. $\mathrm{Br} \mathrm{J}$ Ophthalmol 2003;87(6):747-52.

8. Rema M, Pradeepa R. Diabetic retinopathy: an Indian perspective. Indian J Med Res 2007;125(3):297-310.

9. Sinha AK, Bhatia RPS. Colour vision in diabetes mellitus. Indian J Ophthalmol 1979;27(3):6-8.

10. Shoji T, Sakurai Y, Sato H, et al. Do type 2 diabetes patients without diabetic retinopathy or subjects with impaired fasting glucose have impaired colour vision? the okubo colour study report. Diabet med 2011;28(7):865-71. 